\title{
ANALISIS PERAN KONSULTAN PERENCANA DAN KONSULTAN PENGAWAS TERHADAP KEBERHASILAN PROYEK
}

\author{
Made Novia Indriani, I Nyoman Suta Widnyana, I Putu Laintarawan \\ Program Studi Teknik Sipil, Fakultas Teknik, Universitas Hindu Indonesia \\ madenovia@gmail.com,gussuta@yahoo.co.id, Ltrwnn@gmail.com
}

\begin{abstract}
ABSTRAK
Konsultan Proyek memegang peranan yang sangat penting di dalam keberhasilan sebuah proyek. Tujuan yang hendak dicapai adalah : Untuk mengetahui peranan konsultan pada tahap awal proyek yaitu tahap perencanaan dan perancangan proyek dan untuk mengetahui peranan konsultan, pada tahap konstruksi yaitu tahap pelaksanaan dan pengawasan pembangunan fisik proyek yang dilaksanakan dengan pedoman tepat mutu,tepat waktu dan tepat biaya

Penelitian ini dilakukan untuk menganalisis peranan konsultan perencana dan konsultan pengawas terhadap keberhasilan proyek . Metode yang digunakan dalam penelitian ini adalah metode deskriptif kuantitatif dengan bantuan program SPSS .

Konsultan perencana berkoordinasi dengan baik bersama tim nya dalam melakukan kegiatan antara lain : mengumpulkan data umum proyek seperti data lokasi proyek, fungsi proyek, tujuan proyek, sumber daya yag tersedia dan lain-lain yang berkaitan langsung maupun tidak langsung dalam terwujudnya proyek tersebut, menyusun pedoman persyaratan konstruksi, konsultasi dengan pemerintah terkait dengan perijinan. Pada tahap perencanaan, konsultan perencana, berkoordinasi dengan kurang baik bersama tim nya dalam melakukan : perencanaan arsitektur meliputi denah, tampak, potongan dan detail, perencanaan struktur meliputi perencanaan struktur atas (atap), struktur tengah (kolom) dan struktur bawah (pondasi), membuat Rencana Kerja dan Syarat-syarat (RKS) serta menghitung Rencana Anggaran Biaya (RAB) atau Owner Estimate (OE). Konsultan perencana berkoordinasi kurang baik bersama tim nya dalam membantu panitia untuk menyiapkan dokumen tender dan membantu menyusun jadwal tender pada tahap persiapan tender.

Konsultan pengawas dalam berkoordinasi baik dengan tim nya, dalam melakukan pengawasan terhadap pelaksanaan konstruksi yang meliputi pengawasan mutu bahan, mutu pelaksanaan, serta waktu pekerjaan. Namun memiliki kecenderungan yang rendah pada tahap membuat laporan tentang pekerjaan tambah kurang, tim konsultan pengawas berkoordinasi kurang baik bersama tim yang terlibat. Keberhasilan proyek, kecenderungan nya tinggi jika pihak owner melakukan pembayaran tepat waktu kepada konsultan perencana dan konsultan pengawas. Namun memiliki kecenderungan yang kecil, yang artinya adanya complain yang dirasakan pihak owner dalam melaksanakan kegiatan konstruksi.

Pengawasan memiliki nilai tertinggi, yang artinya peran konsultan pengawas signifikan berpengaruh pada keberhasilan proyek. Model regresi linier berganda $\mathrm{Y}=$ $2,328+0,181 \mathrm{X}_{1}+0,352 \mathrm{X}_{2}$
\end{abstract}

Kata Kunci : Konsultan Perencana, Konsultan Pengawas, Keberhasilan Proyek, 


\section{PENDAHULUAN}

Konsultan Proyek memegang peranan yang sangat penting di dalam keberhasilan sebuah proyek. Tugas sebuah perusahaan konsultan adalah mengawal klien pada tahap awal proyek (tahap perencanaan dan perancangan) untuk mempersiapkan tahap selanjutnya, serta pada masa konstruksi (pelaksanaan pembangunan fisik). Job description konsultan secara umum adalah menerjemahkan keinginan dan kebutuhan klien dengan mendampingi konsultan perencana dalam proses desain yang dituangkan ke dalam dokumen gambar, perhitungan,dan dokumen pendukung lainnya. Kemudian melakukan pengawasan oleh konsultan pengawas dan pendampingan kontraktor pada fase pelaksanaannya. Perencanaan di awal proyek yang matang akan menghasilkan sebuah produk pedoman pelaksanaan yang akurat, yang nantinya akan sangat turut menentukan kesuksesan sebuah proyek.

Konsultan Proyek sebagai pendamping konsultasi bagi owner, maka harus mampu memahami dan menampung semua masukan dari owner, mengawasi dan mendampingi konsultan perencana dalam menuangkannya ke desain. Prosesnya bisa terjadi berulang-ulang, dimana pada umumnya pihak owner memiliki banyak kebutuhan dan keinginan yang harus diakomodasi (apalagi jika klien/owner terdiri dari lebih dari satu orang/pihak terkait, seperti banyak terjadi pada proyek-proyek instansi pemerintahan). Proses diskusi, mendesain, presentasi, revisi desain/mendesain ulang, diskusi lagi dan begitu seterusnya, hampir pasti selalu terjadi pada setiap proyek. Untuk itu, konsultan dituntut harus cerdas menyikapi hal tersebut, agar tidak akan mengganggu pada proses konstruksinya.

Keppres Th 80 No.2003 dan selanjutnya Perpres 54 tahun 2010, terlihat bahwa pekerjaan konsultan juga mempunyai resiko yang cukup besar dari berbagai segi, baik dari segi materiil maupun segi non materiil yang berhubungan dengan ketepatan waktu, kebutuhan tenaga, menjaga kepercayaan, serta kredibilitas perusahaan itu sendiri. Penggunaan konsultan proyek merupakan suatu tim kerja yang memiliki keahlian dalam mengelola manajemen proyek dan bertugas memantau,mengendalikan serta ikut terlibat pada proses proyek. Tim ini yang berfungsi sebagai konsultan dari pelaksanaan proyek di lapangan, dimana peran mereka dimulai sejak tahapan perencanan hingga tahap konstruksi. Namun demikian hal ini suatu realitas, masih saja sering terjadi keterlambatan dan 
penyimpangan kualitas konstuksi pada tahap pelaksanan proyek bukan hanya disebabkan oleh faktor alam, tetapi juga disebabkan oleh beberapa hal antara lain koordinasi, komunikasi,administrasi, pemberdayaan tenaga kerja sebagai sumber daya manusia yang optimal.

\section{Rumusan Masalah}

1. Bagaimana peran konsultan perencana pada tahap perencanaan dan perancangan proyek?

2. Bagaimana peran konsultan pengawas pada tahap pelaksanaan dan pengawasan pembangunan fisik proyek $?$

3. Bagaimana pengaruh peran konsultan perencana dan konsultan pengawas terhadap keberhasilan proyek ?

\section{Tujuan Penelitian}

1. Untuk mengetahui dan memahami peran konsultan perencana pada tahap perencanaan dan perancangan proyek.

2. Untuk mengetahui dan memahami peran konsultan pengawas pada tahap pelaksanaan dan pengawasan pembangunan fisik proyek

3. Untuk mengetahui dan memahami pengaruh peran konsultan perencana dan konsultan pengawas terhadap keberhasilan proyek

\section{TEORI DAN METODE \\ PENELITIAN}

Pelaksanaan Proyek Konstruksi

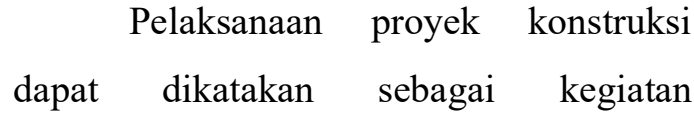
melaksanakan bangunan/konstruksi yang sudah direncanakan sampai dengan terwujudnya bangunan/konstruksi tersebut, agar dapat dipergunakan atau dimanfaatkan oleh individu atau umum. Dalam pelaksanaannya proyek konstruksi akan melibatkan banyak pihak dan akan memberikan kontribusi dalam pelaksanaannya, baik itu lingkungan internal proyek yang bertanggungjawab secara langsung terhadap proses kegiatan proyek, maupun pihak eksternal yang memberikan kontribusi secara tidak langsung terhadap proses kegiatan proyek. Pihak-pihak yang terlibat dalam lingkungan internal proyek dan bertanggungjawab secara langsung terhadap proses kegiatan proyek adalah pihak pemilik proyek (owner) atau prinsipal (employer/client/bouwheer), pihak konsultan (perencana maupun pengawas), pihak kontraktor, sub kontraktor, pemasok (supplier) (Husen, 2009; Latuperissa, 2007; Nurhayati, 2010). Sedangkan pihak eksternal proyek antara lain adalah pemerintah sebagai regulator bagi kelangsungan proyek, institusi keuangan, masyarakat, alam atau lingkungan, media massa, organisasi LSM lingkungan dan sebagainya (Husen, 2009; Latuperissa, 2007).

\section{Owner}


Pemilik Proyek (owner) adalah seseorang atau perusahaan yang mempunyai dana, memberikan tugas kepada seseorang atau perusahaan yang memiliki keahlian dan pengalaman dalam pelaksanaan pekerjaan agar hasil-hasil proyek sesuai dengan sasaran dan tujuan proyek yang ditetapkan (Husen, 2009). Hak dan kewajiban dari pengguna jasa menurut (W. I Ervianto, 2005) adalah:

1. Menunjuk penyedia jasa (konsultan/kontraktor).

2. Meminta laporan secara periodik mengenai pelaksanaan pekerjaan yang sudah dilakukan oleh penyedia jasa.

3. Memberikan fasilitas baik berupa sarana dan prasarana yang dibutuhkan pihak penyedia jasa untuk kelancaran proyek.

4. Menyediakan lahan untuk tempat pelaksanaan pekerjaan.

5. Menyediakan dana dan kemudian membayar kepada pihak penyedia jasa sejumlah biaya yang diperlukan untuk mewujudkan sebuah bangunan.

6. Ikut mengawasi jalannya pelaksanaan pekerjaan yang direncanakan dengan jalan menempatkan atau menunjuk suatu badan atau orang yang bertindak atas nama pemilik.

7. Mengesahkan perubahan dalam pekerjaan (bila terjadi).

8. Menerima dan mengesahkan pekerjaan yang sudah selesai dilaksanakan oleh penyedia jasa jika produknya sudah selesai sesuai dengan apa yang dikehendaki.

\section{Konsultan}

Konsultan adalah orang atau badan hukum yang ditunjuk oleh pengguna jasa yang memiliki keahlian dan pengalaman dalam membangun proyek konstruksi (Husen, 2009). Konsultan menyediakan jasa kepenasehatan(consultancy service) dalam bidang keahlian tertentu. Jadi dalam memberikan jasanya konsultan akan memberikan analisis atau kajian, pendapat atau opini sesuai dengan keahliannya untuk dibuat suatu keputusan oleh pemilik proyek (pengguna jasa).

Konsultan dapat dibedakan menjadi dua yaitu konsultan perencana dan konsultan pengawas (W. I Ervianto, 2005). Sedangkan menurut (Husen, 2009) dibedakan menjadi konsultan perencana, konsultan pengawas dan konsultan manajemen konstruksi. Dengan penjelasan lebih rinci sebagai berikut:

\section{Konsultan Perencanaan}

Konsultan perencana adalah orang/badan hukum yang membuat perencanaan bangunan secara lengkap baik di bidang arsitektur, sipil, dan bidang lain yang melekat erat membentuk suatu sistem bangunan (W.I. Ervianto, 2005). Hak dan kewajiban dari konsultan perencana adalah: 
1. Membuat perencanaan secara lengkap yang terdiri dari gambar rencana, rencana kerja dan syarat-syarat, hitungan struktur, rencana anggaran biaya.

2. Memberikan usulan serta pertimbangan kepada pengguna jasa dan pihak kontraktor tentang pelaksanaan pekerjaan.

3. Memberikan jawaban dan penjelasan kepada kontraktor tentang hal-hal yang kurang jelas dalam gambar rencana, rencana kerja dan syarat-syarat.

4. Membuat gambar revisi bila terjadi perubahan perencanaan.

5. Menghadiri rapat koordinasi pengelolaan proyek.

\section{Konsultan Pengawas}

Konsultan pengawas adalah orang/badan hukum yang ditunjuk oleh pengguna jasa untuk membantu dalam pengawasan pelaksanaan pekerjaan pembangunan mulai dari awal sampai berakhimya pekerjaan yang dilaksanakan (W. I Ervianto, 2005). Hak dan kewajiban konsultan pengawas adalah:

1. Mengadakan pengawasan dan membimbing pelaksanaan pekerjaan.

2. Melakukan Perhitungan kemajuan/prestasi pekerjaan yang dilakukan oleh kontraktor.

3. Mengkoordinasikandanmengendalikan kegiatankonstruksisertaaliran informasi antara berbagai bidang agar pelaksanaan pekerjaan berjalan dengan lancar.

4. Menghindari kesalahan yang mungkin terjadi sedini mungkin serta menghindari terjadinya pembengkakan biaya.

5. Mengatasi dan memecahkan persoalan yang timbul di lapangan agar dicapai basil akhir sesuai dengan kualitas, kuantitas serta waktu pelaksanaan yang sudah ditetapkan.

6. Menerima atau menolak material/peralatan yang didatangkan oleh kontraktor.

7. Menghentikan sementara bila terjadi penyimpangan dari persyaratan yang sudah ditetapkan.

8. Menyiapkan dan menghitung kemungkinan terjadinya pekerjaan tambah kurang.

\section{Konsep Tri Hita Karana}

Secara filosofis peran konsultan perencana dan konsultan pengawas terhadap keberhasila proyek merupakan implementasi dari konsep Tri Hita Karana yang merupakan konsep filosofi Hindu yang universal mengenai hubungan yang harmonis antara manusia dengan Tuhan, manusia dengan manusia serta huungan yang harmonis antara manusia dengan alam.

Hubungan harmonis, komunikasi yang terjalin dengan baik antara sumber daya manusia pada konsultan perencana 
dengan sumber daya manusia lainnya pada konsultan pengawas sangat mempengaruhi keberhasilan proyek, seperti yang terkandung dalam konsep hindu, Tri hita Karana, yang terdiri dari konsep pawongan salah satunya, sebagai konsep ajaran mengenai hubungan manusia dengan manusia yang serasi,selaras dan seimbang agar tercapainya keharmonisan. Adopsi ajaran tersebut mendasari peran dan hubungan antara konsultan perencana dengan konsultan pengawas terhadap tercapainya keberhasilan suatu proyek konstruksi.

\section{Model Penelitian}

Model penelitian merupakan abstraksi dari fenomena-fenomena yang sedang diteliti, adapun model penelitian dapat digambarkan sebagai berikut :

\section{Keberhasilan Proyek (Y)}

Peran Konsultan pengawas

(X2)

Gambar 2.1 Model Penelitian

\section{Metode penelitian}

Penelitian ini dilakukan untuk gambaran secara sistematik agar menganalisis peran konsultan perencana penelitian yang dilakukan dapat mencapai dan konsultan pengawas pada tahapan sasaran yang telah ditetapkan, melalui proyek dan pengaruhnya terhadap suatu alur pemikiran yang logis dan keberhasilan proyek di Bali . Metode yang sistematis.

digunakan dalam penelitian ini adalah Adapun tahapan-tahapan penelitian ini metode deskriptif kuantitatif yang bertujuan untuk membuat deskripsi atau dapat dilihat pada Gambar 2.2. 


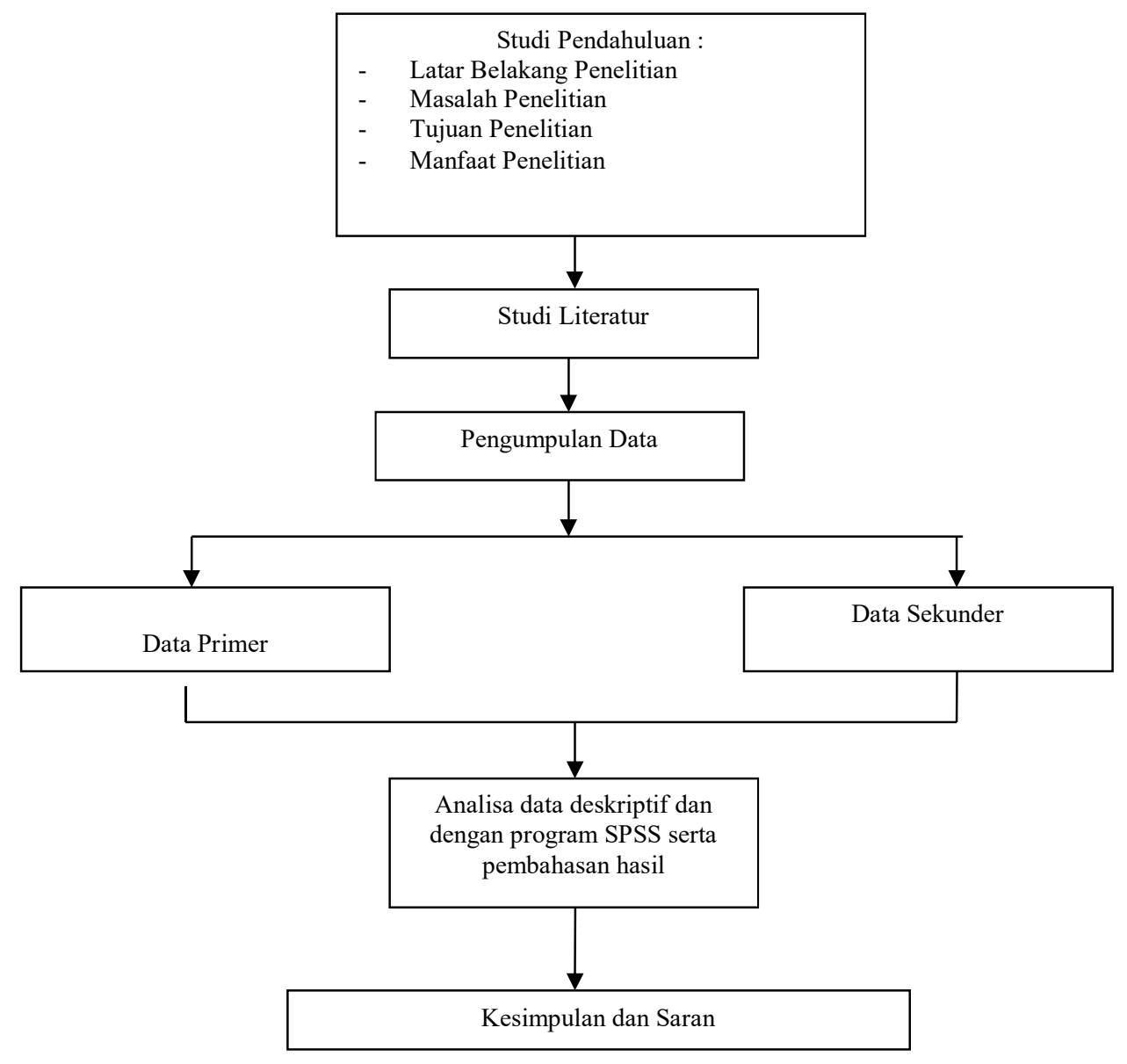

\section{HASIL DAN PEMBAHASAN}

Pengumpulan data primer dilakukan dengan penyebaran kuesioner ke konsultan perencana, konsultan pengawas dan owner. Penyebaran kuesioner dilakukan dengan metode purposive sampling, yaitu menentukan secara acak dengan pertimbangan tertentu sebagai sample atau responden. Adapun respoden yang mengisi blanko kuesioner yaitu sebanyak 30 respoden yang tidak sesungguhnya, untuk pengujian validitas dan reliabilitas. Kemudian setelah instrumen dinyakan valid dan reliabel, dilanjutkan dengan penyebaran kuesioner ke responden yaitu konsultan perencana, konsultan pengawas dan owner sebanyak sepuluh kali jumlah instrumen yaitu sebanyak 130 responden Kuesioner tersebut harus terlebih dahulu diuji validitas dan reliabilitasnya. Untuk pengujian ini diperlukan sampel minimal 30 (tiga puluh) responden untuk mengisi kuesioner yang akan diuji. Kuesioner disebarkan dan ditarik kembali setelah selesai diisi oleh responden dan selanjutnya ditabulasi . Setelah 30 (tiga 
puluh) data tersebut ditabulasi selanjutnya akan diuji menggunakan software IBM

Statistic SPSS Version 13. Syarat minimum uji validitas untuk dianggap Tabel 3.1Hasil Uji Validitas Kuesioner memenuhi syarat apabila $r=0,30$. Adapun hasil uji validitas dan reliabilitas melalui penyebaran kuesioner pada tahap 1, sebagai berikut :

\begin{tabular}{|c|c|c|c|c|}
\hline Variabel & Indikator & r-hitung & r-tabel & Keterangan \\
\hline \multirow{6}{*}{$\begin{array}{l}\text { Konsultan } \\
\text { Perencana }\end{array}$} & $\mathrm{X} 1.1$ & 0,804 & 0,30 & Valid \\
\hline & $\mathrm{X} 1.2$ & 0,713 & 0,30 & Valid \\
\hline & $\mathrm{X} 1.3$ & 0,804 & 0,30 & Valid \\
\hline & X1.4 & 0,627 & 0,30 & Valid \\
\hline & $\mathrm{X} 1.5$ & 0,702 & 0,30 & Valid \\
\hline & X1.6 & 0,630 & 0,30 & Valid \\
\hline \multirow{4}{*}{$\begin{array}{l}\text { Konsultan } \\
\text { Pengawas }\end{array}$} & $\mathrm{X} 2.1$ & 0,737 & 0,30 & Valid \\
\hline & $X 2.2$ & 0,741 & 0,30 & Valid \\
\hline & $\mathrm{X} 2.3$ & 0,693 & 0,30 & Valid \\
\hline & $\mathrm{X} 2.4$ & 0,704 & 0,30 & Valid \\
\hline \multirow{11}{*}{$\begin{array}{l}\text { Keberhasilan } \\
\text { Proyek }\end{array}$} & Y1 & 0,644 & 0,30 & Valid \\
\hline & Y2 & 0,642 & 0,30 & Valid \\
\hline & Y3 & 0,673 & 0,30 & Valid \\
\hline & Y4 & 0,582 & 0,30 & Valid \\
\hline & Y5 & 0,544 & 0,30 & Valid \\
\hline & Y6 & 0,547 & 0,30 & Valid \\
\hline & Y7 & 0,632 & 0,30 & Valid \\
\hline & Y8 & 0,581 & 0,30 & Valid \\
\hline & Y9 & 0,605 & 0,30 & Valid \\
\hline & $\mathrm{Y} 10$ & 0,403 & 0,30 & Valid \\
\hline & Y11 & 0,470 & 0,30 & Valid \\
\hline
\end{tabular}

Sumber : Hasil Analisis 2019

Untuk pengujian validitas, item pertanyaan dikatakan valid apabila nilai corrected item-total correlation memenuhi ketentuan $\geq 0.30$. Tabel di atas menjelaskan bahwa nilai validitas paling terkecil adalah 0,403 dan terbesar adalah 0,804, maka dari itu seluruh item pertanyaan dinyatakan valid.

Instrument yang reliable adalah instrument yang bila digunakan beberapa kali untuk mengukur objek yang sama akan menghasilkan data yang sama. Untuk menguji reliabilitas dalam penelitian ini, dapat digunakan teknik analisis dengan formula cronsbach alpha melalui program computer statistical package for cocial science (SPSS). Suatu konstruk atau variable dikatakan reliable jika memberikan nilai cronbach alpha $>0,60$. 
Tabel 3.2 Hasil Uji Reliabilitas Kuesioner

\begin{tabular}{|c|l|c|c|c|}
\hline No. & \multicolumn{1}{|c|}{ Variabel } & Cronbach's Alpha & Reliabilitas & Keterangan \\
\hline 1 & Konsultan Perencana (X1) & 0,806 & 0,60 & Reliabel \\
\hline 2 & Konsultan Pengawas (X2) & 0,686 & 0,60 & Reliabel \\
\hline 3 & Keberhasilan Proyek (Y) & 0,793 & 0,60 & Reliabel \\
\hline
\end{tabular}

Sumber: Hasil Analisis 2019

Pada uji reliabilitas variabel yang dikatakan reliabel bila nilai Cronbach's Alpha memenuhi ketentuan $\geq 0.60$. Tabel di atas menunjukkan bahwa semua nilai Cronbach's Alpha berada diatas 0,60, sehingga semua variabel dikatakan reliabel.

Analisis statistik deskriptif adalah statistik yang digunakan untuk menganalisis data dengan cara mendeskripsikan atau menggambarkan data yang telah terkumpul sebagaimana adanya tanpa bermaksud membuat kesimpulan yang berlaku untuk umum atau generalisasi. Analisis ini hanya berupa akumulasi data dasar dalam bentuk deskripsi semata dalam arti tidak mencari atau menerangkan saling hubungan, menguji hipotesis, membuat ramalan, atau melakukan penarikan kesimpulan.

Adapun rekapitulasi hasil data, dengan menyebarkan kuesioner ke konsultan perencana, konsultan pengawas dan owner sebanyak130 responden seperti pada Tabel

Tabel 3.3 Hasil Rekapitulasi Pertanyaan Pada Kuesioner I dan II

\begin{tabular}{|l|c|c|}
\hline No & Jumlah responden menjawab 'Ya" & Jumlah responden menjawab "Tidak" \\
\hline X1.1 & 130 & 0 \\
\hline X1.2 & 130 & 0 \\
\hline X1.3 & 130 & 0 \\
\hline X1.4 & 130 & 0 \\
\hline X1.5 & 130 & 0 \\
\hline X1.6 & 130 & 0 \\
\hline X2.1 & 130 & 0 \\
\hline X2.2 & 130 & 0 \\
\hline X2.3 & 130 & 0 \\
\hline X2.4 & 130 & \\
\hline
\end{tabular}

Sumber: Hasil Analisis 2019 
Dari semua pertanyaan mengenai tugas konsultan perencana dan konsultan pengawas yang ditujukan ke 130 responden, semua menyatakan ya, yang artinya pertanyaan dan pernyataan mengenai peran konsultan perencana dan konsutan pengawas dalam pelaksanaaan proyek konstruksi, sudah sesuai.

\section{Frequencies}

\begin{tabular}{|c|c|c|c|c|c|c|c|}
\hline \multirow[t]{2}{*}{ Indikator } & \multicolumn{5}{|c|}{ Skor Jawaban } & \multirow{2}{*}{$\begin{array}{c}\text { Jumlah } \\
\text { Skor }\end{array}$} & \multirow{2}{*}{$\begin{array}{l}\text { Rata- } \\
\text { Rata }\end{array}$} \\
\hline & 1 & 2 & 3 & 4 & 5 & & \\
\hline $\mathrm{x} 1.1$ & 0 & 0 & 0 & 48 & 82 & 602 & 4.63 \\
\hline$\times 1.2$ & 0 & 0 & 5 & 89 & 36 & 551 & 4.24 \\
\hline$x 1.3$ & 0 & 0 & 25 & 85 & 20 & 515 & 3.96 \\
\hline$x 1.4$ & 0 & 0 & 30 & 75 & 25 & 515 & 3.96 \\
\hline$\times 1.5$ & 0 & 0 & 21 & 83 & 26 & 525 & 4.04 \\
\hline$\times 1.6$ & 0 & 0 & 14 & 88 & 28 & 534 & 4.11 \\
\hline \multicolumn{7}{|c|}{$\mathrm{x} 1$} & 4.16 \\
\hline$\times 2.1$ & 0 & 0 & 3 & 83 & 44 & 561 & 4.32 \\
\hline$\times 2.2$ & 0 & 0 & 7 & 95 & 28 & 541 & 4.16 \\
\hline$\times 2.3$ & 0 & 0 & 21 & 70 & 39 & 538 & 4.14 \\
\hline$\times 2.4$ & 0 & 0 & 18 & 64 & 48 & 550 & 4.23 \\
\hline \multicolumn{7}{|c|}{$x 2$} & 4.21 \\
\hline y1 & 0 & 0 & 7 & 71 & 52 & 565 & 4.35 \\
\hline$y 2$ & 0 & 0 & 13 & 89 & 28 & 535 & 4.12 \\
\hline y3 & 0 & 0 & 25 & 75 & 30 & 525 & 4.04 \\
\hline y4 & 0 & 0 & 24 & 75 & 31 & 527 & 4.05 \\
\hline y5 & 0 & 0 & 23 & 71 & 36 & 533 & 4.10 \\
\hline y6 & 0 & 0 & 21 & 79 & 29 & 524 & 4.03 \\
\hline y7 & 0 & 0 & 25 & 68 & 37 & 532 & 4.09 \\
\hline y8 & 0 & 1 & 14 & 83 & 32 & 536 & 4.12 \\
\hline y9 & 0 & 0 & 17 & 88 & 25 & 528 & 4.06 \\
\hline y10 & 0 & 0 & 61 & 49 & 20 & 479 & 3.68 \\
\hline y11 & 0 & 0 & 6 & 96 & 28 & 542 & 4.17 \\
\hline \multicolumn{7}{|c|}{$y$} & 4.07 \\
\hline
\end{tabular}

Sumber: Hasil Analisis 2019

Dari hasil tersebut, dapat dijelaskan bahwa pada variabel peran konsultan perencana dalam berkoordinasi dengan tim nya, kecenderungan nya tinggi pada pada tahap persiapan perencanaan, konsultan perencana berkoordinasi dengan baik bersama tim nya dalam melakukan kegiatan antara lain :
- Mengumpulkan data umum proyek seperti data lokasi proyek, fungsi proyek, tujuan proyek, sumber daya yag tersedia dan lain-lain yang berkaitan langsung maupun tidak langsung dalam terwujudnya proyek tersebut. 
- Menyusun pedoman persyaratan konstruksi.

- Konsultasi dengan pemerintah terkait dengan perijinan.

Namun memiliki kecenderungan yang rendah, yang artinya pada tahap perencanaan, konsultan perencana, berkoordinasi dengan kurang baik bersama tim nya dalam melakukan :

- Perencanaan arsitektur meliputi denah, tampak, potongan dan detail.

- Perencanaan struktur meliputi perencanaan struktur atas (atap), struktur tengah (kolom) dan struktur bawah (pondasi).

- Membuat Rencana Kerja dan Syaratsyarat (RKS)

- Menghitung Rencana Anggaran Biaya (RAB) atau Owner Estimate (OE).

Dan juga konsultan perencana berkoordinasi dengan kurang baik bersama tim nya dalam membantu panitia untuk menyiapkan dokumen tender dan membantu menyusun jadwal tender pada tahap persiapan tender.

Dari hasil tersebut, dapat dijelaskan bahwa pada variabel peran konsultan pengawas dalam berkoordinasi dengan tim nya, kecenderungan nya tinggi pada Konsultan pengawas berkoordinasi dengan baik bersama tim yang terlibat, dalam melakukan pengawasan terhadap pelaksanaan konstruksi yang meliputi pengawasan mutu bahan, mutu pelaksanaan, serta waktu pekerjaan.

Namun memiliki kecenderungan yang rendah pada tahap membuat laporan tentang pekerjaan tambah kurang, tim konsultan pengawas berkoordinasi kurang baik bersama tim yang terlibat.

Dari hasil tersebut, dapat dijelaskan bahwa pada variabel keberhasilan proyek, kecenderungan nya tinggi pada keberhasilan proyek jika pihak owner melakukan pembayaran tepat waktu kepada konsultan perencana dan konsultan pengawas

Namun memiliki kecenderungan yang kecil, yang artinya adanya complain yang dirasakan pihak owner dalam melaksanakan kegiatan konstruksi. Rekapitulasi sebaran data, adalah sebagai berikut. 
Statistics

\begin{tabular}{|c|c|c|c|c|}
\hline & & Perencanaan & Pengawasan & Keberhasilan \\
\hline \multirow[t]{2}{*}{$\mathrm{N}$} & Valid & 130 & 130 & 130 \\
\hline & Missing & 0 & 0 & 0 \\
\hline \multicolumn{2}{|c|}{ Mean } & 4.1560 & 4.2115 & 4.0735 \\
\hline \multicolumn{2}{|c|}{ Std. Error of Mean } & .02793 & .03213 & .02390 \\
\hline \multicolumn{2}{|c|}{ Median } & 4.1700 & 4.2500 & 4.0900 \\
\hline \multicolumn{2}{|c|}{ Mode } & 4.33 & 4.50 & 4.27 \\
\hline \multicolumn{2}{|c|}{ Std. Deviation } & .31850 & .36629 & .27250 \\
\hline \multicolumn{2}{|c|}{ Variance } & .101 & .134 & .074 \\
\hline \multicolumn{2}{|c|}{ Range } & 1.50 & 1.50 & 1.28 \\
\hline \multicolumn{2}{|c|}{ Minimum } & 3.33 & 3.50 & 3.36 \\
\hline \multicolumn{2}{|c|}{ Maximum } & 4.83 & 5.00 & 4.64 \\
\hline \multicolumn{2}{|c|}{ Sum } & 540.28 & 547.50 & 529.56 \\
\hline
\end{tabular}

Berdasarkan hasil analisis statistic tersebut diatas, dapat dijelaskan bahwa :

Jumlah sampel yang digunakan adalah 130 sampel, dengan nilai rata-rata tertinggi pada variabel pengawasan yaitu sebesar 0.3213 , kemudian nilai dispersi rata-rata dari sampel yang tertinggi pada variabel pengawasan sebesar 0.3213, untuk data yang digunakan berdistribusi normal karena masih berada dalam rasio mengetahui hubunganvariabel terikat $\mathrm{Y}$ dengan variabel bebas X1 dan X2. Analisis korelasi yang digunakan adalah analisis korelasi pearson product moment. Setelah koefisien korelasi hasil analisis (r) di peroleh dari masing- skewness berada diantara nilai -2 sampai 2. Dari keseluruhan nilai statistik, pengawasan memiliki nilai tertinggi, yang artinya peran konsultan pengawas signifikan berpengaruh pada keberhasilan proyek.

\section{Hasil Analisis Korelasi}

Setelah data ditabulasi dengan baik, selanjutnya akan dilakukan analisis korelasi yang bertujuan untuk masing variable maka akan dilanjutkan dengan uji t. Nilai $t_{\text {hitun }}$ dirumuskan sebagai berikut:

$$
t_{\text {hitung }}=\mathbf{r} \sqrt{\frac{n-2}{1-r^{2}}}
$$

Setelah $t_{\text {hitun }}$ diperoleh maka hubungan antara variable tersebut.Jika akan dibandingkan dengan nilai $t_{\text {tabel }}$. $t_{\text {hitun }}>t_{\text {tabel }}$ dengan tingkat signifikan Jika $t_{\text {hitung }}<t_{\text {tabel }}$ dengan tingkat $<5 \%$ artinya ada hubungan antara variable signifikan $>5 \%$ artinya bahwa tidak ada tersebut. Ada atau tidak adanya hubungan 
antara variabel dapat dilihat pada table 4.3 di bawah ini :

Tabel 3.4 Analisis Korelasi Terhadap Responden

\begin{tabular}{|c|c|c|c|c|}
\hline \multicolumn{5}{|c|}{ Correlations } \\
\hline & & $\mathrm{X} 1$ & $\mathrm{X} 2$ & $\mathrm{Y}$ \\
\hline \multirow[t]{3}{*}{$\mathrm{X} 1$} & Pearson Correlation & 1 & 0,324 & 0,295 \\
\hline & Sig. (2-tailed) & & .000 & .000 \\
\hline & $\mathrm{N}$ & 130 & 130 & 130 \\
\hline \multirow[t]{3}{*}{$\mathrm{X} 2$} & Pearson Correlation & 0,324 & 1 & 0,410 \\
\hline & Sig. (2-tailed) & .000 & & .000 \\
\hline & $\mathrm{N}$ & 130 & 130 & 130 \\
\hline \multirow[t]{3}{*}{$\mathrm{Y}$} & Pearson Correlation & 0,295 & 0,410 & 1 \\
\hline & Sig. (2-tailed) & .000 & .000 & \\
\hline & $\mathrm{N}$ & 100 & 100 & 100 \\
\hline & 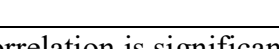 & & & \\
\hline
\end{tabular}

Sumber : Hasil Analisis 2019

Berdasarkan tabel tersebut, maka dapat diuraikan sebagai berikut :

1. Hubungan variabel $\mathrm{Y}$ dengan variabel $\mathrm{X} 1$

Koefisien korelasi (r) variabel $\mathrm{Y}$ dengan variabel Tangible (X1) adalah sebesar 0.295 dengan tingkat signifikansi sebesar 0.000 , ini berarti bahwa terjadi hubungan yang kuat antara variabel keberhasilan proyek (Y )dengan variabel peran konsultan perencana $(\mathrm{X} 1)$.

2. Hubungan variabel $Y$ dengan variabel $\mathrm{X} 2$
Koefisien korelasi (r) variabel $\mathrm{Y}$ dengan variabel konsultan pengawas (X2) adalah sebesar 0,410 dengan tingkat signifikansi sebesar 0.000 , ini berarti bahwa terjadi hubungan yang kuat antara keberhasilan proyek (Y )dengan variabel peran konsultan perencana

3. Hubungan variabel konsultan perencana (X1) dengan variabel konsultan pengawas (X2), koefisien korelasi (r) variabel konsultan perencana (X1) dengan variabel konsultan pengawas (X2) adalah sebesar 0,324 dengan tingkat 
signifikansi sebesar 0.000 , ini berarti bahwa terjadi hubungan yang kuat antara variabel konsultan perencana (X1) dengan variabel konsultan pengawas (X2

\section{Uraian Hasil Analisis Regresi Linier Berganda}

Analisis yang dipergunakan dalam penelitian ini adalah analisis regresi linier Tabel 3.5 Hasil Analisis Regresi Linier Berganda

\begin{tabular}{|l|c|c|c|c|}
\hline \multirow{2}{*}{ Variabel Independen } & Standardized & \multirow{2}{*}{ thitung } & \multirow{2}{*}{ Sig. } & \multirow{2}{*}{ Keterangan } \\
\cline { 2 - 3 } & Coefficients (B) & & & \\
\hline Konstanta (Constant) & 2.328 & 7.083 & .000 & Signifikan \\
\hline Konsultan perencana & .181 & 2.154 & .019 & Signifikan \\
\hline Konsultan pengawas & .352 & 4.185 & .015 & Signifikan \\
\hline R & $: 0,445$ & F & & $: 15,641$ \\
$\begin{array}{l}\text { R Square } \\
\text { Adjused R Square }\end{array}: 0,198$ & Sig. F & $: 0,000$ \\
\hline
\end{tabular}

Sumber : Hasil Analisis 2019

Berdasarkan hasil analisis regresi linier berganda pada Tabel 3.5 dapat dibuat model regresi linier berganda sebagai berikut:

$\mathrm{Y}=2,328+0,181 \mathrm{X}_{1}+0,352 \mathrm{X}_{2}$

1. Nilai konstanta sebesar 2,328 berarti bahwa jika variabel bebas konsultan perencana (X1), konsultan pengawas (X2) bernilai nol atau konstan maka variabel $\mathrm{Y}$ akan sebesar konstanta yaitu sebesar 2,328.

2. Nilai koefisien variabel konsultan perencana $(\mathrm{X} 1)$ sebesar 0,181 berarti bahwa jika variabel bebas konsultan

\section{r}

berganda dengan dibantu oleh software SPSS (Statistical Program for Social Science) versi 13. Tujuan dari analisis ini untuk mengetahui hubungan antara variable dependen (Y) mengenai keberhasilan proyek terhadap variable independen $(\mathrm{X})$ diantaranya X1dan X2. 
Pengujian statistik $F$ bertujuan untuk mengetahui pengaruh secara simultan dari variabel independen terhadap variabel dependen yang ditunjukkan pada tabel ANOVA. Kriteria dari pengujian hipotesis adalah sebagai berikut.

1. Nilai signifikansi $\leq 0,05$ maka hipotesis diterima. Artinya terdapat pengaruh antara variabel independen terhadap variabel dependen secara simultan.

2. Nilai signifikansi $>0,05$ maka hipotesis ditolak. Artinya tidak terdapat pengaruh antara variabel independen terhadap variabel dependen secara simultan

Tabel 3.6 Anova (b) Uji F

\begin{tabular}{|c|c|c|c|c|c|c|}
\hline \multicolumn{7}{|c|}{$\begin{array}{ll}\text { ANOVA }^{\mathrm{a}} \\
\end{array}$} \\
\hline & \multicolumn{5}{|c|}{\begin{tabular}{|l|l|c|} 
Model & Sum of Squares & $\mathrm{df}$
\end{tabular}} \\
\hline \multirow[t]{3}{*}{1} & Regression & 1.893 & 2 & .947 & 15.641 & 0.000 \\
\hline & Residual & 7.686 & 127 & .061 & & \\
\hline & Total & 9.579 & 129 & & & \\
\hline \multicolumn{7}{|c|}{ a. Dependent Variable: Kepuasan Aksesibilitas } \\
\hline
\end{tabular}

Pada tabel Anova di atas dapat diketahui bahwa nilai $F_{\text {hitung }}$ adalah sebesar 15.641 dengan signifikansi (sig.) sebesar 0.000. Tolak $\mathrm{H}_{0}$ jika nilai signifikansi < $\alpha=0.05$. Karena nilai signifikansi lebih dari 0,05 maka menolak $\mathrm{H}_{0}$, sehingga terima $\mathrm{H}_{1}$ yang berarti bahwa kombinasi dari variabel bebas $\mathrm{X} 1$ dan $\mathrm{X} 2$, signifikan digunakan untuk menduga variabel $\mathrm{Y}$. Artinya ada pengaruh secara bersamasama variabel bebas $\mathrm{X} 1$ dan X2 terhadap variabel Y.

Tabel 3.7 Hasil Uji t

\begin{tabular}{|l|c|c|c|c|}
\hline \multirow{2}{*}{ Variabel Independen } & Standardized & \multirow{2}{*}{ thitung } & \multirow{2}{*}{ Sig. } & \multirow{2}{*}{ Keterangan } \\
\cline { 2 - 3 } & Coefficients $(\mathrm{B})$ & & & \\
\hline Konstanta (Constant) & 2.328 & 7.083 & .000 & Signifikan \\
\hline Nyata & .181 & 2.154 & .033 & Signifikan \\
\hline Kehandalan & .352 & 4.185 & .000 & Signifikan \\
\hline R & $: 0,445$ & F & \multicolumn{2}{|c|}{$: 15,641$} \\
R Square & $: 0,198$ & Sig. F & $: 0,000$ \\
Adjused R Square & $: 0,185$ & & \\
\hline
\end{tabular}

Pengujian statistik $t$ bertujuan untuk mengetahui seberapa jauh pengaruh variabel independent secara individual dalam menjelaskan variasi variabel dependen. Berdasarkan dasar signifikansi, kriterianya adalah sebagai berikut:

1. Jika signifikansi $>0,05$ maka Ho diterima, $\mathrm{H}_{1}$ ditolak

2. Jika signifikansi $\leq 0,05$ maka Ho ditolak, $\mathrm{H}_{1}$ diterima

Sumber : Hasil Analisis 2019 
Berdasarkan hasil tabel 3.

Coefficients di atas dapat dijelaskan sebagai berikut:

1. Pengaruh variabel bebas konsultan perencana X1) terhadap variabel $\mathrm{Y}$ Variabel bebas X1 menghasilkan nilai $t_{\text {hitung }}=2,154$ dengan nilai signifikansi (sig) sebesar 0.033. Nilai signifikansi ini lebih kecil dari $\alpha=0.05, \quad$ sehingga dapat disimpulkan bahwa variabel bebas konsultan perencana berpengaruh terhadap variabel $\mathrm{Y}$.

2. Pengaruh variabel bebas konsultan pengawas (X2) terhadap variabel Y Variabel bebas konsultan pengawas (X2) menghasilkan nilai $t_{\text {hitung }}=4,185$

\section{PENUTUP (Kesimpulan dan Saran)}

\section{Kesimpulan}

1. Peran konsultan perencana dalam berkoordinasi dengan tim nya, kecenderungan nya tinggi pada pada tahap persiapan perencanaan, konsultan perencana berkoordinasi dengan baik bersama tim nya dalam melakukan kegiatan antara lain :

- Mengumpulkan data umum proyek seperti data lokasi proyek, fungsi proyek, tujuan proyek, sumber daya yag tersedia dan lain-lain yang berkaitan langsung maupun tidak langsung dalam terwujudnya proyek tersebut.
4. dengan nilai signifikansi (sig) sebesar 0.000. Nilai signifikansi ini lebih kecil dari $\alpha=0.05$, sehingga dapat disimpulkan bahwa variabel bebas konsultan pengawas berpengaruh terhadap variabel $\mathrm{Y}$.

\section{Uji Normalitas}

Hasil uji Normalitas menunjukkan bahwa data terdistribusi normal karena nilai signifikansi uji Kolmogorov Smirnov sebesar 0,324 lebih besar dari 0,05.

Hasil uji Heteroskedastisitas juga menunjukkan bahwa data bebas dari heteroskdastisitas. Hasil ini ditunjukkan oleh nilai signifikansi uji $\mathrm{t}$ pada Uji Glejzer lebih besar dari 0,05.

- Menyusun pedoman persyaratan konstruksi.

- Konsultasi dengan pemerintah terkait dengan perijinan.

Namun memiliki kecenderungan yang rendah, yang artinya pada tahap perencanaan, konsultan perencana, berkoordinasi dengan kurang baik bersama tim nya dalam melakukan :

- Perencanaan arsitektur meliputi denah, tampak, potongan dan detail.

- Perencanaan struktur meliputi perencanaan struktur atas (atap), struktur tengah (kolom) dan struktur bawah (pondasi). 
- Membuat Rencana Kerja dan

- )

- Menghitung Rencana Anggaran Biaya (RAB) atau Owner Estimate (OE).

Dan juga konsultan perencana berkoordinasi dengan kurang baik bersama tim nya dalam membantu panitia untuk menyiapkan dokumen tender dan membantu menyusun jadwal tender pada tahap persiapan tender.

2. Peran konsultan pengawas dalam berkoordinasi dengan tim nya, kecenderungan nya tinggi dalam melakukan pengawasan terhadap pelaksanaan konstruksi yang meliputi pengawasan mutu bahan, mutu pelaksanaan, serta waktu pekerjaan. Namun memiliki kecenderungan yang rendah pada tahap membuat laporan tentang pekerjaan tambah kurang, tim konsultan pengawas berkoordinasi kurang baik bersama tim yang terlibat.

Dapat dijelaskan bahwa pada variabel keberhasilan proyek, kecenderungan nya tinggi pada keberhasilan proyek jika pihak owner melakukan pembayaran tepat waktu kepada konsultan perencana dan konsultan pengawas. Namun memiliki kecenderungan yang kecil, yang artinya adanya complain yang
Syarat-syarat (RKS dirasakan pihak owner dalam melaksanakan kegiatan konstruksi.

Berdasarkan hasil analisis statistic tersebut diatas, dapat dijelaskan bahwa :

Jumlah sampel yang digunakan adalah 130 sampel, dengan nilai rata-rata tertinggi pada variabel pengawasan yaitu sebesar 0.3213 , kemudian nilai dispersi rata-rata dari sampel yang tertinggi pada variabel pengawasan sebesar 0.3213, untuk data yang digunakan berdistribusi normal karena masih berada dalam rasio skewness berada diantara nilai -2 sampai 2. Dari keseluruhan nilai statistik, pengawasan memiliki nilai tertinggi, yang artinya peran konsultan pengawas signifikan berpengaruh pada keberhasilan proyek.

3. Koefisien korelasi (r) variabel $\mathrm{Y}$ dengan variabel konsultan perencana(X1) adalah sebesar 0.295 dengan tingkat signifikansi sebesar 0.000, ini berarti bahwa terjadi hubungan yang kuat antara variabel keberhasilan $\operatorname{proyek}(\mathrm{Y})$ dengan variabel peran konsultan perencana (X1).

Koefisien korelasi (r) variabel $\mathrm{Y}$ dengan variabel konsultan pengawas (X2) adalah sebesar 0,410 dengan tingkat signifikansi sebesar 0.000 , ini berarti bahwa terjadi hubungan yang 
kuat antara keberhasilan proyek (Y )dengan variabel peran konsultan perencana.

Koefisien korelasi (r) variabel konsultan perencana (X1) dengan variabel konsultan pengawas (X2) adalah sebesar 0,324 dengan tingkat signifikansi sebesar 0.000 , ini berarti bahwa terjadi hubungan yang kuat antara variabel konsultan perencana (X1) dengan variabel konsultan pengawas (X2

Model regresi linier berganda $\mathrm{Y}=$ $2,328+0,181 \mathrm{X}_{1}+0,352 \mathrm{X}_{2}$

- Nilai konstanta sebesar 2,328 berarti bahwa jika variabel bebas konsultan perencana (X1), konsultan pengawas (X2) bernilai nol atau konstan maka variabel $\mathrm{Y}$ akan sebesar konstanta yaitu sebesar 2,328.

- Nilai koefisien variabel konsultan perencana $(\mathrm{X} 1)$ sebesar 0,181 berarti bahwa jika variabel bebas konsultan perencana meningkat sebesar 1 satuan sedangkan variabel bebas lainnya bernilai konstan maka variabel Y akan meningkat sebesar 0,181.

- Nilai koefisien variabel konsultan pengawas (X2) sebesar 0,352 berarti bahwa jika variabel bebas Reliability (X2) meningkat sebesar 1 satuan sedangkan variabel bebas lainnya bernilai konstan maka variabel $\mathrm{Y}$ akan meningkat sebesar 0,352

\section{Saran}

Perlu adanya penelitian lanjutan mengenai peran konsultan perencanaan dan konsultan pengawasan yang terkait dengan tugas-tugas untuk mencapai keberhasilan proyek yang efektif dan efisien.

\section{DAFTAR PUSTAKA}

Amudi, P. (1981). Pengantar Statistik (keempat ed.). Jakarta: Ghalia Indonesia.

Ervianto, W. I. (2005). Manajemen Proyek Konstruksi. Yogyakarta: Andi Offset.

Ervianto, W. I. (2005). Manajemen Proyek Konstruksi (Edisi Revisi). Yogjakarta: Andi Offset.

Hansen, S. (2017). Quantity Surveying, Pengantar Manajemen Biaya dan Kontrak Konstruksi. Jakarta: PT Gramedia Pustaka Utama.

Husen, A. (2009). Manajemen Proyek : Perencanaan, penjadwalan, dan pengendalian proyek. Yogyakarta: Andi.

Institute, P. M. (2008). A Guide to The Project Management Body of Knowledge (PMBOK Guide) Fourth Edition. Pennsylvania: Project Management Institut, Inc.

Kerlinger. (2006). Asas-asas Penelitian Behaviour (Edisi 3, Cetakan 7 ed.). Yogyakarta: Gadjah Mada University Press.

Korten, D. C. (1988). Penyusunan Program Pembangunan Pedesaan: Pendekatan

Proses Belajar. Jakarta: Yayasan Obor Latuperissa, J. E. (2007). Kerangka Penentuan Biaya Kontijensi Di Dalam Pelaksanaan Konstruksi. Institut Teknologi Bandung. 
Lock, D. (1983). Manajemen Proyek. Jakarta: Lembaga PPM-Penerbut Erlangga.

Nasional, P. B. D. P. (Ed.) (2008). Jakarta: Pusat Bahasa.

Nugraha, P., Natan, I., \& Sutjipto, R. (1985). Manajemen Proyek Konstruksi 1 (1 ed.). Surabaya: Kartika Yudha.

Nurhayati. (2010). Manajemen Proyek. Yogyakarta: Graha Ilmu.

Soeharto, I. (1997). Manajemen Proyek : Dari Konseptual Sampai Operasional Jakarta: Erlangga.
Sugiyono. (2013). Metode Penelitian Pendidikan Pendekatan Kuantitatif, Kualitatif dan $R \& D$. Bandung: Alfabeta.

Sunarto, R. d. (2007). Pengantar Statistika Untuk Penelitian Pendidikan, Sosial, Ekonomi, dan Bisnis. Bandung: Alfabeta.

Tamin, O. Z. (2000). Perencanaan dan Pemodelan Transportasi (kedua ed.). Bandung: Institut Teknologi Bandung. 